\title{
FROM THE CLASSROOM TO THE WORKPLACE: HOW SOCIAL SCIENCE STUDENTS ARE LEARNING TO DO DATA ANALYSIS FOR REAL
}

\author{
JACKIE CARTER \\ University of Manchester \\ jackie.carter@manchester.ac.uk \\ MARK BROWN \\ University of Manchester \\ mark.brown@manchester.ac.uk \\ KATHRYN SIMPSON \\ University of Manchester \\ kathryn.simpson-2@manchester.ac.uk
}

\begin{abstract}
In British social science degree programmes, methods courses have a bad press, and statistics courses in particular are not well-liked by most students. A nationallycoordinated, strategic investment in quantitative skills training, Q-Step, is an attempt to address the issues affecting the shortage of quantitatively trained humanities and social science graduates. Pedagogic approaches to teaching statistics and data analysis to social science students are starting to indicate positive outcomes. This paper contributes to these debates by focusing on the perspective of the student experience in different learning environments: first, we explain the approach taken at the University of Manchester to teaching a core quantitative research methods module for second-year sociology students; and second, we introduce case studies of three undergraduates who took that training and went on to work as interns with social research organisations, as part of a Manchester Q-Step Centre initiative to take learning from the classroom into the workplace.
\end{abstract}

Keywords: Statistics education research; Statistical literacy; Internships;

Workplace learning

\section{INTRODUCTION}

\subsection{TEACHING OF QUANTITATIVE RESEARCH METHODS}

The ability to find use and interpret data critically (demonstrating statistical literacy) is a highly desired graduate attribute. As more social data emerge, and skills to collect, analyse and interpret these data are sought after, graduates with the ability to critically evaluate such data will be increasingly in demand in the labour market. With overcrowded curricula in university-degree programmes, it is a challenge to provide opportunities for students to practise the skills they acquire in the classroom. Is there a crisis in university social science students learning quantitative analysis? It would appear so, in the UK at least. Concerns over a dearth of quantitative skills among social science

Statistics Education Research Journal, 16(1), 80-101, http://iase-web.org/Publications.php? $p=$ SERJ

(C) International Association for Statistical Education (IASE/ISI), May, 2017 
graduates have been raised in a series of high-profile reports from government, research councils and employers stretching back three decades (ESRC, 1987; HEFCE, 2005; Mills, Jepson, Coxon, Easterby-Smith, Hawkins, \& Spencer, 2006; MacInnes, 2009). The report Count Us In: Quantitative Skills for a New Generation sets out a vision of "A generation of citizens, consumers, students and workers as comfortable with numbers as they are with words" (British Academy, 2015). Considerable reflection among educators over the way quantitative data skills are taught in schools, colleges and universities, has ensued. A national initiative, Q-Step (Nuffield, 2013) has been funded as a step-change intervention programme to help universities train undergraduate social science and humanities students in quantitative data skills. Fifteen centres, and three affiliate centres, hosted in UK universities, are tasked with testing innovative, experimental approaches to teaching, the aim of which is try to make a difference and turn the tide on teaching quantitative methods.

The University of Manchester hosts one of these centres. Our response to this challenge is underpinned by two core principles: first, to expose all social science students from the start of their degree to quantitative data and skills teaching and, second, to put in place training for future quantitative researchers. We want to find the future researchers and teachers who can develop quantitative capacity in university education, as well as in the professions that engage in social research. This paper illustrates our approach, with reference to second-year sociology students, and through case studies our emphasis on learning in the workplace is described.

\subsection{LEARNING QUANTITATIVE SKILLS}

Two elements of our approach to teaching are explored. First, the teaching of quantitative methods in the classroom, and the computing lab, is developed around substantive areas of interest to the students (for example, around national or global inequalities, or differences in attitudes to social issues such as migration). This builds on the growing body of research that highlights the importance of locating the teaching of statistical thinking and concepts within meaningful context (Neumann, Hood, \& Neumann, 2013). It is in the applications that students gain the crucial motivation for learning statistical techniques, and seeing their relevance and usefulness. The second element builds from this and concerns the choice of data. The importance of the data used in teaching is easily overlooked but if students are to learn statistics in an applied setting we need to source data that are carefully matched to the applications. Fortunately a greater commitment to open data alongside technological advances in access to data have made this much easier, with new forms of data visualisation (e.g., Ridgway, 2015) opening up exciting ways to engage students in statistical thinking.

The approach means that we move away from teaching 'what is a mean / median / mode' to 'what are the characteristics of this social phenomenon, and how can numeric data be used to explore and describe it?' The quantitative understanding then becomes a means to an end. Both aspects of our approach (the importance of context and the use of real data) are supported by recommendations from the influential Guidelines for Assessment and Instruction in Statistics Education (GAISE) (Carver et al., 2016), endorsed by the American Statistical Association. While the GAISE guidelines are intended to apply across all subject areas of statistical education, we contend these two aspects are particularly pertinent when teaching statistics to social science students, where the barriers of statistics anxiety and perceived irrelevance of statistics require thought be given to contextualisation of the statistical concepts and techniques being taught. 


\subsection{PRACTISING QUANTITATIVE SKILLS}

A second pillar of our approach is that of developing the practice of quantitative skills. Some of this takes place in computer labs, following lectures, as described above. Building on this, an approach, introduced through the Q-Step Centre, is to take the learning from the classroom into the workplace, through undertaking an applied researchfocussed, data-led project. Through this experiential learning we are discovering how undergraduates apply their statistical understanding through practical application in social research environments. A sub-set of students has the opportunity to undertake an 8-week paid internship at the end of their second year. To date 116 students have been placed in public, private and third-sector work environments, undertaking social research including quantitative analysis. We have conducted post-internship in-depth interviews with 18 of these students, and have collected reflective learning logs from another 90.

The combination of the approach to teaching with real-world data, contextualised by substantive social issues, together with extending that learning to the workplace, provides a rich opportunity for us to better understand how students learn about the application of quantitative skills. Our results are encouraging and through the case studies included here (and others collected) we can start to identify the educational paths our future social researchers may take to become statistically literate. Our ultimate aim must be to feed this back into the social science curriculum, and develop our own practice through reflecting on what works, and what does not, and why.

\section{CURRICULUM DEVELOPMENT: RE-THINKING THE WAY OUR STUDENTS ENCOUNTER STATISTICS IN THE CLASSROOM}

\subsection{THE PROBLEM}

While most social science degree programmes now include some quantitative training as a compulsory part of the curriculum, for many students, the quantitative methods module can appear disconnected from the rest of the curriculum, a course to be endured and passed, rather than an integral part of learning their chosen degree subject.

Historically, this has been reflected in a tendency for low student satisfaction on these courses and the fact that few students choose to take more advanced quantitative options in their final year or use quantitative approaches or data analysis in dissertations (MacInnes, 2009). In considering the possible reasons for the unpopularity of quantitative methods some studies have highlighted a degree of anxiety about the prospect of learning statistics, often associated with bad memories of school mathematics. In a national study of sociology undergraduates, Williams, Payne, Hodgkinson, and Poade (2008) found more than half reported being anxious about statistics, and this concurs with our own polling of students (see Section 2.3). A degree of anxiety at the start of a quantitative methods course is not unexpected given that most students on UK social science degrees (outside economics) will not have studied any mathematics or statistics since the age of 16. However, our own experience (and the data from the Williams et al. study) suggests that the more fundamental barrier to learning has been the perception among many students that quantitative approaches are simply not relevant to their core subject interests. This alienation has arguably been reinforced where the teaching of statistics has been focussed on understanding a set of techniques and measures without proper contextualisation in substantive applications. This is reflected in the GAISE report, where a number of the recommendations directly address the challenge of making statistics 
relevant (by teaching statistics as an investigative process, and using real data to provide context and purpose).

\subsection{ENQUIRY-LED AND DATA-DRIVEN}

At Manchester, supported by a series of externally funded teaching innovation grants, we have sought to develop a model of statistical training that responds directly to the problems of disengagement and the recommendations for change formalised in the GAISE report, which focuses on student engagement through the use of motivating data and a problem-based learning approach. In practice we do this by leading with the substantive themes rather than statistical topics and by using real-world data to investigate topical and meaningful questions, questions that connect to the themes and theories they are studying in their substantive curriculum, be it sociology, politics or criminology. Once students are engaged in this process we observe the dissipation of statistics anxiety in the classroom, particularly once they are reassured that the statistics they will encounter in conducting applied quantitative research are very different from the abstracted formula and equations remembered from their school mathematics classes. This is evident in our classroom interactions with students and indirectly in the positive course evaluation we receive (see below). Our revised curriculum draws directly on some of our own experiences at the University of Manchester (Buckley, Brown, Thomson, Olsen, \& Carter, 2015) but we recognise many of the same motivations and pedagogic thinking in the work of others in the UK (e.g., Adeney \& Carey, 2011), and worldwide (Parker, Dobson, Scott, Wyman, \& Landén, 2008; and Carver et al., 2016). While the move to more data-driven and enquiry-led teaching has been influenced by pedagogic considerations it has been facilitated by a revolution in the supply of digital social data and greater provision of computer labs for teaching. This latter point is important since the time to source and prepare teaching data along with a lack of suitable teaching rooms had previously been identified as key factors constraining the greater use of real-world data (Rice \& Fairgrieve, 2001).

\subsection{THEORY TO PRACTICE: SURVEY METHODS IN SOCIAL RESEARCH}

The application of our teaching approach is illustrated with reference to "The Survey Method in Social Research", a compulsory course taken by all sociology students at the University of Manchester, developed and taught by one of the authors of this paper. The students, who take it, are typical of many social science undergraduates in having studied largely non-quantitative humanities subjects at A-Level (i.e., their pre-university courses). A low proportion of the class have studied mathematics beyond the age of 16 .

A class survey administered at the start of the course (2014/2015 cohort) reveals the extent of negative preconceptions and uncertainty with almost half the class reporting anxiety about the prospect of quantitative analysis (and another fifth unsure) and just $25 \%$ stating they would have taken the course if it were optional (Table 1).

Table 1. Attitudes and preconceptions about quantitative methods -2014/15 cohort $(N=59$ with 39 non-respondents)

$\begin{array}{lccc}\text { The idea of analysing quantitative data } & \text { Agree } & \text { Disagree } & \text { Neither agree nor disagree } \\ \text { on a computer makes me anxious. } & 47 \% & 32 \% & 21 \% \\ \text { If this course had been optional, } & \text { No } & \text { Yes } & \text { Not sure } \\ \text { would you still be taking it? } & 44 \% & 25 \% & 31 \%\end{array}$




\subsection{REAL-WORLD DATA FOR TEACHING FROM THE UK DATA SERVICE}

Our approach in the Survey Methods in Social Research course is heavily dependent on the availability of relevant and topical data that will engage students. Fortunately, the UK has a large and expanding supply of social data that can be used in teaching. A major source for the social sciences is the UK Data Service (UKDS), which holds a vast archive of both quantitative and qualitative data, licensed for use by educators and students, and some of this under open access. The service includes a rich range of government survey data sets, both UK and international, on topics we know our students are interested in. Crucially, developments in the user-interface have made this data increasingly accessible to non-specialist users. Having previously been a key resource for research academics, the UKDS now represents a valuable resource for enquiry-based learning and teaching for undergraduate students.

With the aim of showcasing the breadth of data available, the first lab-based session on the course challenges students to develop a research question around a topic of interest to them (perhaps drawing on a substantive module they have a particular interest in) and then using the UKDS to search for relevant data to investigate their question. It is very rare for students to pick a topic for which a search does not return some relevant data. As well as an individualised experience demonstrating the relevance of secondary data to the student's own interests, the exercise engages them in a critical part of any research project - sourcing a suitable data set - which is frequently omitted from quantitative modules that tend to focus just on data analysis, often with pre-prepared, well-behaved data sets. Finding relevant data is a key skill, which students acquire through this approach. The UKDS site is used in a follow-up practical in which students use the online documentation for the data set they found (user guides, methodology reports and questionnaires) to critically evaluate the suitability of their data for the proposed research question. Again this exercise confronts students with issues that are a fundamental part of research, such as assessing the representativeness of samples, considering the validity of measures and problems of missing data. The enquiry-based approach used replicates the way data-led projects frequently present themselves in real-world research settings. Writing up this exercise as a research design forms the first of two assessed project assignments, one that can be later developed for a dissertation proposal.

The research design provides a natural lead into the second part of the course, which considers how a data set can be analysed to answer a research question. While many students would like to use the data they have sourced in the first part of the course, in practice this is not viable. Given the large class size (around 100 students) and introductory nature of the course, many of the data sets found by students will have complex structures that are unsuited to analysis at this level. This rationale is shared and we hope motivated students might return to these issues in higher-level courses if their appetite has been whetted.

This places great importance on the choice of survey used for teaching. Fortunately the huge range available makes it possible to select a survey that is matched to the interests of the class and topical issues. The Health Survey for England (HSE), Crime Survey for England and Wales (CSEW), and British Social Attitudes (BSA) survey have all been used on this course. In fact, the UK Data Service provides a range of off-theshelf teaching data sets that are prepared from the originals with a reduced set of variables for use in introductory teaching, as well as teaching case studies (see UKDS, 2016). However, with a little work one can customise one's own data set with the advantage of being able to select a wider selection of variables adapted to the substantive themes of interest. Some teaching resources have been created and shared through the 
Enriching Social Science Teaching with Empirical Data project (ESSTED, 2016). Recent topical themes investigated in class using the BSA include 'trust in politicians', following the parliamentary expenses scandal, and attitudes towards welfare and inequality, in the context of recession and austerity policies. In each case substantive themes are used to develop research questions that in turn direct the analysis. While the class all work on the same themes, workshop guides provide considerable flexibility for students to develop their own lines of enquiry through their choice of additional variables. In the end-ofmodule assessed project, learning and application is personalised further as students apply the skills learned in class to their own research question by selecting their choice of variables, all the time drawing from a common data set, which the lecturer is - due to preparatory work - familiar with.

In this example of application-led teaching, we are relying exclusively on secondary data to engage our students. Our motivation here is to both showcase the richness, wide topic coverage and ease of access to relevant secondary data, and to challenge a prevailing culture we observe among students that doing original research requires that they collect their own data. This had resulted in very few final students using secondary data analysis in final-year dissertations (Wathan, Brown, \& Williamson, 2011). Putting secondary data centre stage in our courses enables us to highlight the content and design elements of the large-scale studies that make them ideal sources for dissertation research, with all the advantages of large and nationally representative samples and professionally designed and tested measurement tools. Nonetheless, we recognise that alternative pedagogic approaches emphasise the value of teaching statistics as part of an enquiry-led research process, which incorporates primary data collection (Wild \& Pfannkuch, 1999; De Veaux \& Velleman, 2008). This approach, now embedded in the New Zealand school curriculum and supported by CensusAtSchool NZ (Ministry of Education, 2007; n.d.), situates the learning of statistical concepts and techniques within a "statistical enquiry cycle" in which students are engaged in defining a problem and then a plan to design and collect the data to answer it, followed by analysis and interpretation of results (Wild \& Pfannkuch, 1999). The New Zealand model demonstrates there is more than one way to incorporate real-world data into the teaching of statistics. Whether the data is derived from primary collection or secondary sources, a common feature of both approaches is the framing of statistical learning objectives within a meaningful application.

\subsection{TEACHING STATISTICS FROM THE SUBSTANTIVE CONTEXT}

In terms of statistical content, the level of techniques covered on the course is basic, going no further than cross-tabulation with use of control variables and a chi-square test of association. We teach students to operationalise their substantive research questions as testable hypotheses, drawing on their own subject knowledge to develop these and identify the required dependent and independent variables. Statistical concepts (such as variation and inference) and techniques (like cross-tabulation, the use of a control variable and a chi-square test) are encountered in context, and as part of a coherent research process in which the students are active, enquiry-led participants. Learning statistics becomes the means to an end rather than an end in itself.

While the course includes a conventional series of face-to-face lectures, the applied learning takes place in the lab classes, where students gain understanding and confidence through experimentation and practice. In terms of lecture content, for this course we make a conscious decision to teach statistics without use of formal statistical notation or an emphasis on formula. Rather, the focus is deliberately on which purpose a measure serves in the research process, and how it is interpreted. The limitations of the 
exploratory techniques covered are highlighted and the value of more sophisticated methods, like regressions, discussed and signposted for those interested in specialist options in year 3 .

\section{PRACTISING QUANTITATIVE SKILLS IN THE WORKPLACE}

\subsection{PAID INTERNSHIPS}

One of the hallmarks of the Q-Step Centre is the introduction of paid summer internships to work on research projects that require quantitative skills applied to social data. This intervention builds upon existing pedagogic literature (see, e.g., Curtis \& Blair, 2010) by rethinking work-placement learning, and designing short, embedded, researchled and data-driven projects carried out in external organisations. Internships and work-

placement learning provide a powerful pedagogical tool. Students are afforded real-world experiences in public, private and voluntary sector organisations, which they can use to illustrate and compare concepts and theories they learn about in the classroom, thereby enriching their understanding of the subject-matter taught in their academic courses, and grounding this in practice in a work environment. With strong drivers in higher education pressing educators to demonstrate the acquisition of graduate attributes, the opportunity to undertake a work placement or internship as part of a degree course is attractive to many current and prospective undergraduates.

What differentiates the University of Manchester Q-Step internship from other programmes is their design around real-world social research projects.

\subsection{RESEARCH-LED PROJECTS}

Social science students have undergone internships as part of sandwich degrees over the past thirty years. However, two influential reports on sandwich education have made substantial criticisms of this type of placement; firstly, that there is a lack of integration between the sandwich placement and academic course content (Department of Education and Science, 1985) and, secondly, as a consequence of the lack of integration the placement itself can be an excessively specialised experience (Council for National Academic Awards, 1985). The Q-Step Centre has placed emphasis on embedding quantitative concepts and techniques into social science courses and developing researchled internships that build on this approach.

There are many benefits to students on research-led internships with perhaps two prominent aspects: experiencing a workplace environment first-hand, and undertaking authentic research projects for their placement providers. Students are expected to be independent researchers, as well as working with a team, undertaking social science enquiry in a real-world context. In developing students' research skills and capabilities a research-led placement provides students with short but powerful narratives that are incredibly useful for personal development planning, job applications and interviews (Knight \& Yorke, 2004; Rook, 2016). A research-led approach to placements focuses on the development of higher-order skills, which can be a more effective means of enhancing employability compared to simply spending time in a workplace undertaking generic activities (Curtis \& Blair, 2010). Enabling undergraduate social science students to apply their statistical knowledge in a supportive work environment is largely unchartered territory, and one which we set out to explore. 


\subsection{Q-STEP INTERNSHIPS: WHO, WHERE AND WHEN}

In 2014 the Q-Step Centre at Manchester University introduced its first year of paid internships; 19 students were hosted in social research organisations in the public, private and voluntary sector, for 6-12 weeks across the summer at the end of their second year, in London and Manchester. To apply for an internship, students needed to meet two eligibility requirements. First, as a condition of our funding, they had to be studying on a degree programme in one of the subject areas represented in our Q-Step Centre bid (this included sociology, politics, criminology, philosophy, social anthropology and linguistics). Second, they also needed to have taken at least one course unit that included a component of statistical training (a list of courses meeting this criterion was published on our website). While this helped incentivise our quantitative course options, we ensured the list included some courses with entry-level statistical content, reflecting our primary concern that internships should be open to as wide a pool of students as possible and not just those with strong quantitative skills and experience.

Following the success of this pilot year, the number of internships was increased to 48 in 2015 and 49 in 2016, involving a wider range of participating organisations. Figure 1 shows the number of internships in each year, by programme of study. Further information about which organisations students were placed in can be found at Manchester Q-Step Centre (n.d.).

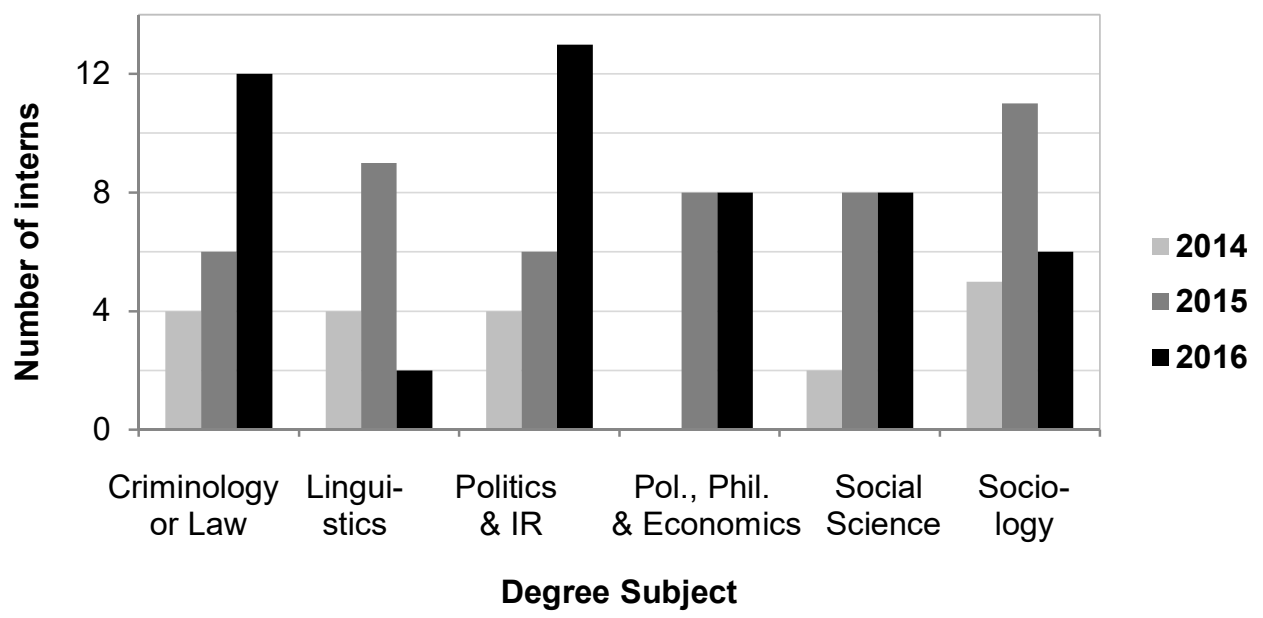

Figure 1. Q-Step summer internships 2014-2016 by degree studied

Unlike more generic work-placement programmes, the Q-Step internship projects are all designed to develop skills in handling and analysing statistical data. The projects are co-developed with the Q-Step team of academics and the host organisations. All students who undertake an internship are required to apply - as if for a job - for the research project position. They are shortlisted, if suitable, and interviewed by a member of the academic team and the host organisation. Subject to being a satisfactory candidate (as defined by their overall grades being $60 \%$ or higher, and satisfying the host organisation that they are suitable for the position), they then spend the agreed time (typically eight weeks) undertaking a data-driven, research-led project for the organisation. In the 2014 cohort, 19 students were placed out of 25 who applied (with three of those not selected finding alternative internship opportunities). Supervision is provided by the host as well 
as by the Q-Step academic mentor. At the end of the internship students are asked to develop a poster to capture the main findings from their research. An event is then held in the autumn where students, their host organisation and other interested parties are invited to celebrate the outcomes of the internships. The internships are not formally assessed.

At the end of the first year of running the internships, we secured additional funds to interview all the students and some of the employer organisations. In the case of the students, these semi-structured interviews were designed to explore whether they had been impacted by their internship opportunities, and if so how, and whether the experience had motivated them to continue learning more about quantitative data analysis. Of the 18 interviews we present here findings from three. These three cases are selected on the basis that first, each one undertook the social survey research methods module described; and second, they illustrate the effect of an internship on both 3rd-year undergraduate course options, and postgraduate choices.

The results are not intended to be representative, and in fact reflect three students who were well-disposed to mathematics in their prior education. We are cognisant of the need to follow up these findings with longitudinal surveys of the students as they progress through different pathways to their postgraduate careers, and to include students who were less well-inclined towards mathematics at the outset. Nonetheless, this is a starting point from which we can seek to develop a feedback loop to help inform us, and others, of the effect of situated, applied learning in the context of quantitative methods for social research. It also reflects the small cohort we had in the first year of the internships, which was always likely to reflect the well-motivated students who were prepared to put themselves forward for a new initiative, and therefore, and perhaps especially for sociology students, likely to be positively disposed to mathematics.

\subsection{POST-INTERNSHIP INTERVIEWS}

A research assistant (one of the co-authors) was appointed to conduct the 2014 summer interns' interviews. Students were invited to interview and all but one (through illness) participated. Face-to-face interviews took place in spring 2015 when students were entering their final undergraduate semester at the university. The same questions were asked through a semi-structured interview lasting about 40 minutes, of all students, covering the following themes, with the opportunity to probe more deeply around each area:

Background and context. A-levels (formal exams taken at aged 17 and 18), attitude to mathematics and statistics, degree programme. Motivations for applying for an internship.

Taught experience. Prior modules: which eligible modules for a Q-Step internship were studied. Data experience: clarifying, which data and software they were familiar with before and during the internship.

Internship experience. General questions about the experience and three things they learned. Research-specific questions, which data, software and methods were used. What did students gain from doing the internship. Skills: data and other skills - what did they learn.

Application. As a result of the internship did attitudes to quantitative methods change, and will the student pursue further opportunities to develop their quantitative skills.

We did not explicitly ask students about the link between what they were taught in their academic course and how useful this was on placement. In part this was because students had come to the internships from a range of courses and taught modules and we were less interested about the specific statistical concepts and techniques they had been 
taught than we were in the way they had applied their understanding, whichever modules they had taken.

These three case studies are drawn from second-year students, all of whom had taken the survey methods course and all of whom were studying single or joint honours sociology for their degree subject.

- Pete, placed in Manchester City Council's Age Friendly team together with two other Q-Step interns.

- Natassia, placed at a university in London working with the National Survey of Sexual Attitudes and Lifestyles (Natsal) Survey research group.

- Bella, placed in a consultancy organisation in London who specialise in conflict, post-conflict and fragile environments.

\section{CASE STUDIES}

\subsection{MANCHESTER CITY COUNCIL AGE-FRIENDLY TEAM}

Pete was one of three students who participated in a team of Q-Step interns in a research project to locate sources of data in support of the Manchester City Council Age Friendly Team's work on developing policy initiatives for Manchester, which was designated an age-friendly city in 2010 as part of the World Health Organisation (WHO) Age-friendly Cities initiative, the first of nine in the world.

On his subjects prior to university, Pete studied A-levels (qualifications taken at the end of formal education) in Government \& Politics, Philosophy and History. His motivations for undertaking an internship were clear and focussed on his future:

I liked that it was a vocational way of using social sciences and at that point what I was thinking about was what I was going to do with my degree and if I stopped at the undergraduate level where would I be with it. So I thought this was a good way to improve my CV, get some experience, and give the degree a bit of a definition as to what kind of applicant I could be when I leave university in terms of applying for jobs.

He described the work carried out on the project:

I worked with other Q-Step students on a project with the Age-Friendly-Manchester team, which worked on an initiative set by the WHO for making Manchester an agefriendly city. They brought us in to work on developing, monitoring and assessing how good a job they were doing and how age-friendly the city is. The project mainly involved piloting an indicator-based approach, finding what data was out there that could be used as a performance indicator for the Age-Friendly Team and that was done in consultation with documents, which were done in consultation with the WHO. Then testing then to see if the approach worked and writing it all up in a report.

...

We didn't do a lot of analysis. It was a lot of finding data. Then, when we did have it, particularly census data, we used Excel. Mostly to play with data and create graphs and charts and to recode it, things like that. There wasn't a lot of analysis. We didn't do a regression.

He continued on how it connected to the work undertaken in the classroom:

I think the experience in general ... to see how some of these ideas that we talk about in lecture theatres, in classrooms, are used in the world, and how what we do not just relates to the outside world but quite a meaningful world too. It was great to work with a team who cared so much about what they were doing, and this wasn't just 
market research, it was the ability to use our skills in industry but also that we were contributing to a wider cause so I really enjoyed that.

He was realistic that the project was less about data analysis and more about finding good sources of data for subsequent policy-led research, and commented that the first part of the survey methods course had prepared him well for that task.

It was a good opportunity to learn about some of the difficulties in working with secondary data in particular. That was something that became quite apparent ... due to budget and data [restrictions], we could dig up from what was available. It led to quite a few problems about the comparability of data and how available it was and when you can find things that can be broken down by location but not by age and we need both so all those sorts of things. So it was learning experience as to what is reasonable to expect from secondary data and what is out there and on the flip side of that it was good to learn just what you can do with some of these skills and what is available.

Speaking with the supervisor for this team of students on a visit to see them presenting their work, it was evident that Pete had played a leading role in the team, and risen well to the rather loosely-defined challenge set to them. His confidence in sourcing data, learned in the classroom through the exercises with the UK Data Service, had primed him to be able to critically analyse secondary data, and be aware of sophisticated issues such as comparability and validity.

Pete's experience enabled him, on finishing the internship, to evidence his skills and land a job, in his third year, as a research assistant with a student accommodation search engine company in Manchester. His role was to trawl through and analyse student satisfaction surveys.

After his internship Pete undertook a series of social statistics modules in his final year, though he chose not to do a data-driven dissertation, not because he wasn't comfortable with numbers, but because his interests were also theoretical. On being asked about the benefits of developing a quantitative skill set he spoke about this setting him apart from other sociology graduates:

There's a lot of sociologists but not many with good quant skills ... it's always a good idea to strengthen your resume. And also on a more academic level some of these courses have been good to better understand numbers and spot things in the news and everyday life really in terms of what's good practice and bad practice and where numbers can strengthen arguments and reports and where they can cloud them or where they are used as smoke and mirrors. I feel more discerning now when it comes to statistics and numbers.

Pete graduated in 2015 and is now studying full-time on a master's in Social Research Methods and Statistics course, in order to continue to develop his quantitative skills - a choice in which he says his Q-Step experience was instrumental - and considering undertaking a $\mathrm{PhD}$ in the future.

Pete came to statistics and quantitative methods from a position of being comfortable with mathematics in school, but not selecting to further this skill set at university until QStep provided the opportunity. In fact he had avoided studying statistics as he found it "a bit scary" but having selected second-year options, including the course on survey methods, this helped him to "turn sociology knowledge into an applied thing". Pete feels he is now getting going with this new found skill and confidence, and it has enabled him to put in motion his interest in sociological research in an applied way. He sums this up as "how to use methods to solve social puzzles." 


\subsection{UCL CENTRE FOR SEXUAL HEALTH AND HIV RESEARCH, LONDON}

Two students were placed with the UCL Centre for Sexual Health and HIV Research, based in the Research Department of Infection and Population Health. Le Lu was studying linguistics and sociology, and Natassia was studying sociology. This case study focusses on Natassia's experience since she was on the BA in social sciences programme and had taken the Survey Methods in Social Research course.

Natassia had studied French, theology, art, business and biology prior to attending university. She was confident with mathematics although she had not studied it since she was 16 . She had not really known what to study at university, though, and sociology was a fairly random choice, but she was enjoying her course. Her reasons for applying for an internship were not the data analysis or applied research, but rather that she saw this as an opportunity to gain some work experience:

I thought it might be fun to do an internship, have a job; it wasn't the quants or the statistics that drew me in, it was more going somewhere to work as I had never done that before.

Although she applied for other internships, she was extremely clear that the one she succeeded in being appointed to was the right one for her - and this was entirely due to what interested her in her studies:

That internship was my dream. It was the only one that was to do with sex and sexuality as that's what I focus on in sociology and I saw that one and I thought yes this is the perfect internship. Given our own choice of research topics, I have always chosen something to do with sexuality or STIs. So when I saw the UCL and Natsal topic area, I thought that's it, I don't want to do anything else.

The drive to learn more about sexuality motivated Natassia. She (and Le Lu) completed the project that had been created for them within three weeks of starting the internship. In part this was because they were fast learners, but also because they came so wellprepared, statistically, although they had not conveyed the extent of their knowledge at interview. Their UCL mentor and supervisor commented that they got through some of the work surprisingly quickly:

From their applications, we were not expecting them to be as strong as they actually were when they arrived so I don't know whether that's to do with the way they presented themselves or their CVs but we definitely had, from the interviews and from the feedback that I'd got from the interviews, I was told probably don't expect them to be able to do too much complicated analysis and then they came and they really could.

$\ldots$

So all of this is analysing Natsal and its complex survey data so there's lots of different analyses you can do ... and we thought they might do some basic descriptive analysis and then move on to more complex kind of adjusted regression analysis, you know, so we're thinking about confounders and things, but actually they kind of whizzed through that. They were really keen, they were really interested in adjusting for confounders and thinking about confounders ... they picked that up really quickly.

In class Natassia had learned to use SPSS (for descriptive statistics) and UCINET (for social network analysis) and on the internship she was taught to use Stata. This was a good learning opportunity but quite a steep learning curve. Nonetheless, it enabled her to acquire an appreciation for learning syntax, and the skills associated with statistical analysis beyond pointing-and-clicking. When asked if she felt she had the skills to undertake the internship, her response conveyed this: 
I wasn't trained to use Stata at Manchester, I was trained to use SPSS and at UCL they only use Stata. Stata is not visual whereas SPSS is, so I had to learn how to type a series of commands, which seems scary but actually it's not and it took me a couple of days to get my head around it .... but I wasn't frightened because I just assumed that they would tell me how to use it. Yes, in the fact that I understood why surveys are conducted and why people are going to use that data and how people interpret the results. I understood the basic foundations of that before I went into the internship so on that level I was pretty confident.

This response shows a sophisticated level of understanding. She appreciated that she had been trained to use a software tool in her courses, but that this gave her a scaffold to learn other tools, albeit through a different approach (command line rather than through a visual graphical user interface). She was also confident that support would be provided and this belief enabled her to open up to learning new methods and tools. Of note in her approach is her willingness and appetite to be challenged - an attitude that continued to serve her well throughout the placement.

The area of research she worked on enabled her to explore age differences at first heterosexual intercourse and contraceptive use. Her work involved statistics including, but also going beyond, the level of data analysis she had studied in the classroom.

I did simple crosstabs, regression, measured change over time so I had to combine the two data sets, which was incredibly difficult! It took me weeks! And I never want to do it again! But it was really satisfying.

In fact, her analyses of the prevalence and factors associated with reporting using emergency contraception has since been taken forward by another researcher at UCL and has been submitted as an article to a peer-reviewed journal, with Natassia as a co-author.

An opportunity was afforded to the interns towards the end of their placement when they were asked to present their work to their peers. Although nervous, by her own admission, Natassia saw this as another chance to stretch herself. She had already spent time thinking carefully about presentation of numerical data, and statistical analyses through tables and charts, and the importance of writing up a methods section for a publication with great care. The internship afforded her the chance to give a presentation to a professional audience.

I put a lot of preparation into it, and did a lot of practice. I presented to the whole department so lots of people that I didn't work with. It was on all of the projects I did when I was at UCL. It was terrifying but I am so glad that they made me do that. I felt it was the kick I needed to push me over that hurdle. It's not something to be scared of and it's good practice. ... I was nowhere near as nervous as I thought I was going to be when I started and I got really good feedback and got e-mails back and I generally felt really good afterwards.

Natassia continued in her third year to undertake quantitative courses, where available to her, and completed a quantitative dissertation saying that her internship experience at UCL showed her that she wanted to do this type of analysis. She was also able to use the Q-Step helpdesk at Manchester for support with methodological issues including weighting her data. On her next steps after her degree she said:

I decided to apply for the SRMS (Social Research Methods and Statistics) master's course. I had to do this. It was designed for me to do it.

Her drive to develop her statistical knowledge further is compelling and uplifting. She sees her dream job as being in social research - and would love to work for Google or in Silicon Valley, and bring the skills learned there back into a career where she 'can help other people and contribute to something bigger'. In summing up her experiences to date, she feels strongly that to do quantitative data analysis: 
... you don't have to be brilliant at maths. If you're fairly logical in the way you think

it will make sense to you, even if you have to read it a few times.

And on the impact of the internship: and,

... without the internship I wouldn't have had a dissertation,

The Q-Step project had everything to do with me choosing to do a master's in social research methods and statistics.

Natassia's experience motivated us to develop a short video clip, to use as inspiration for other students and to communicate more widely the success of her internship. Other students' stories are also captured on the Q-Step website (Manchester Q-Step Centre, n.d.).

\subsection{INTEGRITY RESEARCH AND CONSULTANCY, LONDON}

Integrity Research and Consultancy provides the third case study. Integrity is a London-based ethical research consultancy, which provides localised research in fragile, post-conflict, and hard-to-access environments. Their work combines field-research experience with academic rigour across three continents. Projects undertaken vary according to the needs of their clients, which include governments, developmental organisations and corporates.

Bella had her pick of internships, having been interviewed for and offered three. She chose Integrity because it offered something different, and she liked that it was a smaller organisation undertaking international development research.

I thought it would be very well suited to what I can actually do and what would be important for me to learn unlike some big companies who put you into a predetermined role that I may not necessarily know anything about and I really liked that it would be using statistics and data analysis as I am really interested in that. I

had three quantitative modules last year (year 2).

She had chosen to do as many quantitative options in her first two years as she was able to, in part because she was competent and confident at mathematics. Bella had studied the International Baccalaureate before coming to university and had taken mathematics beyond the age of 16 . In this respect she differed from most of the students on the surveys course, and demonstrated a natural aptitude for and confidence in mathematics, as well as a keen interest in her subject, sociology.

Bella's experience of the internship was extremely positive. She got on well with her colleagues and enjoyed the diversity of the work they were engaged in. Whilst their expertise was chiefly around qualitative research methods, Bella was able to apply her quantitative knowledge in a variety of ways, both on the placement and subsequently (when she continued to undertake work for them). She also contributed to the qualitative research undertaken by Integrity, especially in the area of advising on sampling framework.

One of the biggest things I was working on, and the project, which I stayed and worked on, was working on a big body of qualitative interviews ... There were interviews with 100 participants, very, very in-depth, and I produced reports and summarised the overall statistics [for these].

I became the go-to person, for example, for sampling techniques and things like that and I loved that.

Here we should add that students were given support from their academic Q-Step mentor. She was at liberty to draw on expertise back at the university, and did so in terms of asking for reference materials on quantitative and qualitative research methods. It is 
fair to say though that Bella was applying her understanding of the methods course in the workplace, and stretching herself in doing so.

Bella experienced real-world research in a fast-moving environment, where work is commissioned and often undertaken in a responsive fashion. Because of the short nature of the placement, she did not get to see the results of all of her work, though she did have experience of designing research.

Everything I did I worked as part of a team ... the things I did were more related to methodology and designing methodology than actual analysis ... there were a couple of projects that we were assigned to do, which I contributed to designing the research methodology, the research design, the surveys and the sampling design, and I left before I could get the results and the actual outcome.

From Integrity's point of view, they were positive about the experience:

So I don't think there was any analysis task that we assigned her with that she wasn't able to perform to a high-level of quality. ... I just think the concept of doing the academic theory and then trying to put it into practice in a company like ours, is exactly what the balance should be to prepare somebody for the workplace and apply it commercially.

Bella had studied social statistics modules as part of her degree course, and after the internship proceeded to undertake a quantitative dissertation. She collected and evaluated twitter data on conversations surrounding the Israeli-Palestinian conflict and explored how different groups interact, how different networks shape the discourse around the topic on social media and how these are structured. She took a cross-sectional sample of relational tweets (i.e., mentions and replies) between users on the topic of the case study and used these to model relations between users in a directed social network. She also undertook a content analysis of the tweets, quantifying frequencies of keywords and phrases.

Although it's likely that she would have undertaken a quantitative dissertation without having done a Q-Step internship, that Bella is now (one year after graduating) studying for a master's in social research methods and statistics indicates her continued enthusiasm for quantitative social science. She recognised the value of having undertaken an internship in an organisation that focuses more on qualitative research methods, and the experience helped her to think through her own career choice:

I taught a few people how to do sampling, just the basics. So, what makes a statistically representative sample, what confidence intervals are, just simple things like that, very basic statistics.

... just doing all these things, the sampling, the methodology, that's what I want to be doing for my career and in that sector as well. I never really knew what I wanted to work as, I was always unsure, and knowing that I have a sector, which I am quite passionate about and something I am good at and something, which I can get better at is good to know. ... I've always thought it's good to be good at maths, it helps you in all areas of your life, not necessarily applying the maths but the thinking involved.

After the internship Bella had other work experience that was made possible directly through the contacts she made whilst at Integrity, and also in quantitative methods and data management activities. Her internship benefited her beyond the placement.

\section{FINDINGS}

This paper set out to explore the connection between teaching quantitative research methods in the classroom and the computer lab, and application of that learning in the workplace. The case studies selected sought to investigate whether our sociology students 
can, with some training at undergraduate level, practise their skills in social research environments and deepen their learning of statistics. Our findings centre around the core themes that were introduced in the questions posed to students, whilst also reflecting on what this means to us as educators. The wider context is that of employers, but their perspectives and the relevance of this work to the labour market, is left to another paper.

\subsection{ATTITUDE TO MATHEMATICS AND MOTIVATION FOR INTERNSHIPS}

All three cases included here were positively disposed to mathematics and statistics. One had a stronger background than the others and had sought out social statistics courses. One had previously felt comfortable with mathematics and had opted for social statistics courses as he perceived them to have value to differentiate his skill set from other sociology graduates, even though he thought the courses were a little scary. And the third had been good at mathematics at school but had not considered the value of quantitative modules in her degree, and was drawn to an internship because of the work experience opportunities it afforded. Hence, coming from different motivations and perspectives, and having positive but varying levels of confidence with mathematics, our three students reflected the cohort of students who chose to put themselves forward for an internship (a cohort who as a result of self-selection, we recognise, are likely to be more well-disposed to mathematics than their peers). They all share a strong interest in their substantive subject (here sociology) and curiosity to find out more about how they can apply their learning beyond what they have learned in class. As we can observe from their testimonies, the driver for their success was the desire to explore social research questions; sexuality, age-friendly policy initiatives, and international development research in conflict-ridden zones. The data and analysis skills were a means to achieving this - not a starting point in and of themselves.

The three examples do not, however, reflect students who were less well-inclined towards mathematics and learning statistics. The small cohort size meant we were unlikely to attract many such students in the trial year of the programme. We did have at least one student who met the criteria for this paper (studies sociology, had taken the survey methods course and did an internship) but was less positive about her previous mathematics experience. Concerns over disclosure for this student mean we have not included her as a case study for this paper; we will, however, consider the less-positively disposed to mathematics in future work when we have collected more data.

\subsection{RELEVANCE OF THE SURVEY-METHODS COURSE}

The big question for us, and others, is to find out whether what we are teaching students is of direct applicability in the workplace. This is particularly pertinent to Q-Step with employability being a cornerstone upon which the success of the programme will be measured, in part given that employers' demands for more quantitatively-skilled graduates is such a driving force behind the investment.

Prior to revamping the curriculum, however, it has been valuable to observe its current relevance. All three of the case studies drew directly on the teaching from the course. Discovery of secondary data sets was a core part of Pete's placement - and his ability to critically evaluate data sources, see their strengths and limitations - was a direct result of the first part of the methods course. In Natassia's case, she was able to start with the statistical skills she had learned on the course (albeit in SPSS not Stata) to immediately undertake some analysis of the Natsal data, and use this as a foundation for developing more sophisticated analyses, and extending her toolkit to acquire the 
competencies to run a new software package. And whilst Bella undertook less analysis in her placement, she applied her understanding of sampling and research design in a way that directly benefited her host organisation. Hence, the learning acquired in the course was indeed fit-for-purpose in the workplace.

Moreover, the emphasis on the substantive research question as the starting point on the taught course appears to reflect practice in the workplace.

\subsection{INTERNSHIP EXPERIENCES: STUDENTS, EDUCATORS AND EMPLOYERS}

There is much to be drawn from the three case studies presented, but we reflect here on the core themes for teaching statistics and quantitative methods. The experience of our Q-Step internships provides a rare and valuable insight into the extent to which classroom training is equipping students with the relevant skill set to enter the labour market upon graduating. Q-Step internships through the partnerships developed, provides an opportunity for a three-way dialogue and feedback loop between students, educators and employers. This paper focuses predominantly on the first two, with the employers setting the wider context, and providing the basis for a further paper.

Students While internships were set up as an opportunity for students to practise and apply their data skills in a workplace setting, we underestimated the extent to which they would be environments for the learning of new skills. From the case studies presented here (and the many others not reported), the findings show that, when students are motivated through research that is meaningful and resonates with their interests, there is an extraordinary capacity for rapid and effective learning of new skills that can take them well beyond the comfort zone of their taught syllabus. This is exemplified in the case of Natassia, where having started the internship with experience in simple exploratory analysis using SPSS, she came back having learned and applied multiple regression modelling using STATA. To do this in 8 weeks is a remarkable achievement. To have her work built on and contribute to a co-authored paper is testament to the ability of a highlymotivated and capable student. The aspirations of Q-Step internships should be this high, where this is achievable (and we have similar examples across the wider cohort). Other examples of sophisticated analysis include complex merging of data sets, data cleaning and creation of derived variables.

Our students have shown themselves to be capable, with the right support, of undertaking social research in all its messiness and complexity. The starting point for all these cases was a social survey research methods course (sometimes with other social statistics courses); the end points were analyses, presentations, research papers and jobs beyond the 8-week placement, and, for all three of our case-study students, postgraduate research training in social research methods and statistics, by choice.

Educators How does this experience feed back into the development of the curriculum? We would argue that the case studies provide a clear endorsement of our conviction that classroom teaching of methods should aim to replicate as far as possible the environment and process of real social research. The sense of students as active participants in that process, with responsibilities for problem solving and decision making is informing how we apply this learning to our teaching. We believe that statistical education in social science should be a process through which statistical concepts and techniques are learned through their application in the context of a wider process that is led by substantive research questions. 
There are clearly limits on how far this can really be done in a classroom setting with large classes. However, we can identify some general principles. Data skills need to be taught and learned in the context of meaningful applications - that means the careful selection of data sets and research questions that match to the interests of our students. It also means, and this is challenging, avoiding the temptation to use overly-sanitised teaching data sets and a formulaic approach to teaching statistics. In the real world the test of good data skills is more about the ability to define and solve data problems in the context of messy and frequently incomplete data.

UK Data Service We previously made reference to the UK Data Service (UKDS) from which data are extracted for teaching the survey methods course. The need for students to conduct data analysis in a real-world context, as evidenced through the three case studies presented here, highlights the demand for relevant and topical data, which can be used in a wide variety of social science teaching. The UKDS has already developed a suite of teaching and learning guides and worksheets as well as online data skills and modules to help students learn and develop statistical techniques. Now the UKDS is creating and updating its teaching data sets for use in the classroom as well as providing information on how teachers can create their own teaching data set. It is also introducing dedicated resources for students addressing key thematic social science research issues. The results in this paper validate the direction being taken by the UKDS in support of teaching, and we will continue to ensure that lessons learned from use of data in the workplace feed back into service developments.

Lessons for statistical and data literacy The internship experiences reported here cast light on the fact that the data skill set is ever-changing, not least as more social data and big data become available. Methods teaching in social science courses, in the UK, is fairly traditional, built mostly around the classic secondary analysis of survey microdata using licenced software like SPSS. What we have found is that for many (especially smaller) organisations, these packages may not be available, with much more use made of tools like Excel, Google forms and in some case open-source tools like R. This came to light when we consulted with host internship organisations, when we asked for key skills and software tools they would look for. They unanimously asked for Excel, with a lower number requesting SPSS. However, whilst students may have experience of Excel, we were not previously teaching this in any formal way. Since 2015 we have built this into our pre-internship training workshops, and expect to integrate some basic Excel training into the core curriculum.

We have taken this opportunity to critically reflect on our own teaching, especially in consideration of use of technology and tools for data manipulation, analysis and visualisation. Moreover, we are looking for good and innovative teaching practice to consider how we can build on the students' enthusiasm for the substantive elements in their courses, and use classroom and lab time judiciously to provide more opportunities for applied learning. For example, flipping the classroom to enable students to apply their statistical knowledge on real-world data is a direction of travel for the Manchester Q-Step team, as is developing more confidence with handling numeric data in our social science cohorts. The short films we have developed from previous Q-Step interns are designed to help students see how their peers have succeeded (student stories at Manchester Q-Step Centre, n.d.), and to motivate others to follow suit. 


\subsection{REFLECTIONS ON TRANSFERABILITY OF THE INTERNSHIP MODEL}

We acknowledge that the internship model reported here has been made possible due to external funding with additional contributions from our university, and the implementation and sustainability of such an approach opens up many questions. Some of these we are currently dealing with ourselves, such as how to quantify the value of an internship to all involved in order that a co-funding approach could be explored, leading possibly to a fully-funded model where the host organisation pays. An alternative model would be to integrate internships into the core curriculum, though this would present significant challenges related to the need for formal assessment (including the timetabling of internships in relation to examination boards in June). Our experiences highlight a number of matters that need to be considered from the outset for those planning to run such a scheme.

To assess or not The University of Manchester programme does not formally assess work-placed learning, i.e., the internships are not credit-bearing. We are keeping this under consideration, and know that other schemes - including some within the Q-Step programme - do assess the work done whilst on placement, often through development of a research report or dissertation. Indeed assessment and quality assurance of the placement experience (for all concerned) opens up a rich area of further research. We do have evidence that more students have the confidence to undertake quantitative or mixedmethods research in their final degree year as a consequence of the learning experience from the internships, but this remains to be explored through separate analysis.

Coordination and support of internships The internship coordinator at the Q-Step Centre is allocated $50 \%$ to this role. Considerably more time than this was devoted to the setting up of the programme in the first two years, and in the third year additional staff resource through a research assistant was deployed at the time of advertising projects and interviewing candidates. The work is seasonal, insofar as the busiest periods are pre- and during the placements. All interns are assigned an academic mentor (from the Q-Step team or $\mathrm{PhD}$ expertise in the department) to support the students whilst on placement. The academic lead also convenes and delivers an annual event, which celebrates the students' achievements. This work requires investment and a team approach and can be undertaken with colleagues in careers, though we contend that running this from an academic department is beneficial. Perhaps the greatest effort required from the outset is developing relationships and trust with the organisations who will host the interns, and managing expectations of all concerned. Our experiences have taught us that organisations appreciate the light-touch approach we have developed and that students need less support from us if they join a team that already has a good level of quantitatively trained staff. Where this expertise is less evident, students need to draw more on academic input.

\section{CONCLUSIONS}

We have already seen that a more hands-on approach to learning quantitative methods has resulted in more engaged and motivated students who are able to overcome their concerns about their limited mathematics or statistical knowledge prior to undertaking the course by learning-through-doing data analysis. Unit Evaluation Questionnaire (UEQ) scores (a survey conducted on all courses at the University of Manchester and the main instrument for measuring student feedback) for the survey methods course discussed here bear this out. Countering the widespread assumption that compulsory quantitative methods modules are unpopular with students we observe consistently high levels of 
student satisfaction being reported in the UEQ exercise since the course was redesigned (for 2014/15 the UEQ mean score for 'Overall, I would rate this unit as being excellent' was 4.22 (compared to a mean of 3.96 for all courses in the school). Building on this we have developed opportunities for students at undergraduate level to put their skills into practice in the workplace through paid internships.

Our key objective for Q-Step at Manchester is to develop statistically literate graduates, starting from a low base (often students have studied no mathematics beyond the age of 16) and to help train future quantitative social researchers. We believe that the combination of classroom-based teaching and applied learning in the computer lab, followed by work-placed research-led and data-driven social research, is a strong foundation for developing analytical graduates who can undertake statistical research. The approach requires well-motivated students with interests in social research questions, strong teaching, and opportunities to apply their learning creatively in the workplace. All students approach this knowing that it will involve application of number to social research questions; their varying attitudes to mathematics requires further exploration. Internships or work-experience programmes also require investment of time and money, resources that should not be underestimated.

We have shown that students, who are willing to be challenged and stretched, can learn and apply advanced statistical techniques (including statistical modelling) from a low base in a relatively short time. Low confidence at the start of a course, or an internship, is not a barrier to being able to undertake quantitative data analysis, and indeed basic statistical techniques (up to simple linear regression) provide a good foundation on which to build. Our three case-study students all saw the statistics and mathematics they had been taught as enabling them to undertake their social research projects, and talked about it helping them to solve puzzles, or think analytically even though they had to persevere with this on occasions.

We contend that compared to a more conventionally taught statistics course, our enquiry-based approach to learning foundation statistics using real-world data provides students with a skill set that is more easily transferred to, and built upon in, the workplace setting where data problems rarely present themselves in the manner of a statistics textbook. The internships, we are creating, provide the ideal opportunity to evaluate that claim, and we shall continue to explore this as we develop our internship programme. Not only do our students gain from this approach, but so too do employers in the public, private and voluntary sector as this body of statistical knowledge, critical awareness and analytical mindset is taken into these organisations.

Finally, whilst our research centres on the teaching of statistical concepts to social science undergraduates, we believe that all statistics educators can learn from our experience. With the introduction of national initiatives such as Core Maths (in England), and the continued push for evidence-based policy formation in government departments, the findings reported here are timely. We argue that to create a workforce-ready statistically literate graduate population, it would be wise to focus on the application of learning in the workplace, as we have done here.

\section{ACKNOWLEDGEMENTS}

We acknowledge that the Nuffield Foundation, ESRC and HEFCE funded the Q-Step Programme, and the University of Manchester Centre for Higher Education, Research Innovation, and Learning (CHERIL) funded the project with the interviews of the students whose case studies appear in this paper. The University of Manchester's Directorate for the Student Experience co-funded the internships. Special thanks go to all the students in the 
internships, and especially to Pete, Natassia and Bella for their time and permission to include their stories and names in this paper. Finally, we recognise the organisations who hosted our students on internships, and in particular University College London, Manchester City Council's Age-Friendly Team, and Integrity Research and Consultancy for permission to use them as case studies here. All quotes are shared with permission.

\section{REFERENCES}

Adeney, K., \& Carey, S. (2011). How to teach the reluctant and terrified to love statistics: The importance of context in teaching quantitative methods in the social sciences. In G. Payne \& M. Williams (Eds.), Teaching quantitative methods: Getting the basics right (pp. 85-98). London: Sage Publications.

Buckley, J., Brown, M., Thomson, S., Olsen, W., \& Carter, J. (2015). Embedding quantitative skills into the social science curriculum: Case studies from Manchester. International Journal of Social Research Methodology, 18(5), 495-510.

British Academy (2015). Count us in: quantitative skills for a new generation. British Academy urges UK government to address numeracy crisis.

[Online: www.britac.ac.uk/news/news.cfm/newsid/1285]

Carver, R., Everson, M., Gabrosek, J, Horton, N., Lock, R., Mocko, M., Rossman, A., Rowell, G. H., Velleman, P., Witmer, J., Wood, B. (2016). Guidelines for assessment and instruction in statistics education (GAISE) college report 2016. Alexandria, VA: American Statistical Association. [Online: www.amstat.org/education/gaise]

Curtis, S. \& Blair, A. (Eds.) (2010). The scholarship of engagement for politics: placement learning, citizenship and employability. Birmingham: The Higher Education Academy Network. [Online: papers.ssrn.com/sol3/papers.cfm?abstract_id=2085623]

Council for National Academic Awards (1985). Supervised work experience in CNAA first degree courses. London: CNAA Development Services Publication.

Department of Education and Science (1985). An Assessment of the costs and benefits of sandwich education. The Rise Report. London: Department of Education and Science.

De Veaux, R. \& Velleman P. (2008). Math is music; statistics is literature (or, why are there no six-year-old novelists?). Amstat News, 375, 54-58.

ESSTED (2016). Enriching social science teaching with empirical data. The University of Manchester. [Online: www.projects.socialsciences.manchester.ac.uk/essted/]

ESRC (1987). Horizons and opportunities in the social sciences. London: Economic and Social Science Research Council.

HEFCE (2005). Strategically important and vulnerable subjects: Final report of the advisory group. Higher Education Funding Council for England. [Online: image.guardian.co.uk/sys-files/Education/documents/2005/06/28/shortage.pdf]

Knight, P. \& Yorke, M. (2004). Learning, curriculum and employability in higher education. London: Routledge Falmer.

MacInnes J. (2009). Proposals to support and improve the teaching of quantitative research methods at undergraduate level in the UK. London: Economic and Social Research Council (ESRC).

Manchester Q-Step Centre (n.d.). Internships. The University of Manchester. [Online: www.humanities.manchester.ac.uk/q-step/internships/]

Manchester Q-Step Centre (n.d.). Student stories. The University of Manchester.

[Online: www.humanities.manchester.ac.uk/q-step/student-stories/] 
Manchester Q-Step Centre (2015). What is a career with quants like? Social science Qstep students. The University of Manchester.

[Online: www.youtube.com/watch? $v=p L B d J e F j Z F I \&$ feature=youtu.be]

Mills, D., Jepson, A., Coxon, T., Easterby-Smith, M., Hawkins, P., \& Spencer, J. (2006). Demographic review of the UK social sciences. London: Economic and Social Research Council (ESRC). [Online: core.ac.uk/download/pdf/278774.pdf]

Ministry of Education (n.d.). CensusAtSchool NZ. [Online: new.censusatschool.org.nz/]

Ministry of Education (2007). The New Zealand curriculum. Wellington. NZ: Author. [Online: nzcurriculum.tki.org.nz/The-New-Zealand-Curriculum]

Neumann, D. L., Hood, M., \& Neumann, M. M. (2013). Using real-life data when teaching statistics: Student perceptions of this strategy in an introductory statistics course. Statistics Education Research Journal, 12(2), 59-70.

[Online: iase-web.org/Publications.php?p=SERJ_issues]

Nuffield Foundation (2013). Universities awarded $£ 19.5$ million for overhaul of quantitative social science training. A step-change in quantitative social science skills. [Online: www.nuffieldfoundation.org/news/universities-awarded-\%C2\%A3195million-overhaul-quantitative-social-science-training]

Parker, J., Dobson, A., Scott, S., Wyman, M., \& Sjöstedt-Landén, A. (2008). International bench-marking review of best practice in the provision of undergraduate teaching in quantitative methods in the social sciences. Staffordshire, England: Keele University.

Rice, R, Burnhill, P, Wright, M. \& Townsend S. (2001). An enquiry into the use of numeric data in learning and teaching: Report and recommendations for UK higher education. Edinburgh: University of Edinburgh.

Rice, R. \& Fairgrieve, J. (2001). An enquiry into the use of numeric data in learning and teaching. Radical Statistics, 81, 18-33. [Online: www.radstats.org.uk/no081/rice.pdf]

Ridgway, J. (2015). Implications of the data revolution for statistics education. International Statistical Review, 84(3), 528-549.

Rook, S. (2015). Work experience, placements and internships. London: Palgrave MacMillan.

Scott Jones, J. \& Goldring, J. (2015). 'I'm not a quants person': key strategies in building competence and confidence in staff who teach quantitative research methods. International Journal of Social Research Methodology, 18(5), 479-494.

Wathan, J., Brown, M., \& Williamson, L. (2011). Increasing secondary analysis in undergraduate dissertations. In G. Payne \& M. Williams (Eds.), Teaching quantitative methods: Getting the basics right (pp. 121-141). London: Sage Publications.

Wild, C. \& Pfannkuch, M. (1999). Statistical thinking in empirical enquiry (with discussion and a response from the authors). International Statistical Review, 67(3), 223-265.

Williams, M., Payne, G. Hodgkinson, L., \& Poade, D. (2008). Does British sociology count? Sociology students' attitudes toward quantitative methods. Sociology, 42(5), $1003-1021$.

JACKIE CARTER

School of Social Sciences, University of Manchester Oxford Road, Manchester, M139PL 